\title{
Need for empirical evidence to support use of social license in conservation: reply to
}

Garnett et al.

Dave Kendal ${ }^{1,2 *}$, Rebecca Ford ${ }^{2}$

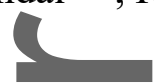

${ }^{1}$ Geography and Spatial Sciences, School of Technology, Environments and Design,

Geography Building, University of Tasmania, Clark Road, Sandy Bay, TAS 7005, Australia

${ }^{2}$ School of Ecosystem and Forest Sciences, The University of Melbourne

*email dave.kendal@utas.edu.au

Running head: Social License

Article Impact Statement: Understanding the role of social license informs managers and

policy makers of community support and acceptance of conservation actions.

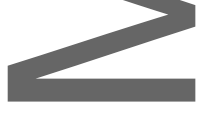

Kendal et al. (2017) argue that the use of the term social license in conservation needs critical

evaluation and highlight the utility of social constructs such as social acceptance in

understanding public support for conservation activities. Garnett et al. (2018) argue that

social license is a distinct concept, best conceptualized as a binary "emergent property of

political interactions before and during the operations of an enterprise." They argue that the

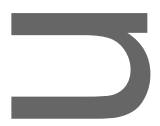

This is the and mascript accepted for publication and has undergone full peer review but has not been thr o t t copyediting, typesetting, pagination and proofreading process, which may lead to differences betw this version and the Version of Record. Please cite this article as doi:

10.1111/cobi.13114.

This article is protected by copyright. All rights reserved. 
license metaphor is a useful one; a social license is a necessary precursor to a regulatory license, and it is something that can be granted and withdrawn. There are aspects of this argument that are worthy of further exploration, particularly the conceptualisation of social license as an emergent property of relationships between civil society and conservation actors. However, their expectations that an emergent social license would be binary and recognisable are inconsistent with the vast majority of scholarship on the concept.

\section{$\mathcal{C}$}

Garnett et al. propose a new definition of social license that is a substantial departure from definitions that are currently expressed in the literature - government interprets whether a license is granted by civil society when deciding whether to provide legal rights for an activity. This definition is based on assumptions about the relationship among governments, civil society, and other actors that need to be tested and that are not supported by existing research. Theindefinition assumes that social license will be explicit enough that it is possible to gauge whether civil society has granted permission for an activity and that governments are closely involved in conservation and attuned to social license. Critical evaluations of use of the term social license repeatedly highlight that although it may be easy to identify the absence of a social license by the presence of conflict, a lack of conflict does not necessarily mean a social licence is present (e.g., Parsons \& Moffat 2014; Moffat et al. 2016; Overduin \& Moore 2017). Empirical observations of social licenses have consistently described them as intangible, impermanent, and often fragile (Moffat et al. 2016; Overduin \& Moore 2017) and highlight that it is difficult to identify whether a social license is being maintained over time. Garnett et al. recognise this issue in their idea that any mandate from the community for longterm conservation arrangements (e.g. covenants) could erode over time, but how would one 
know this? Overduin and Moore (2017), recently explored a range of perspectives on social license in watershed management. They found that water conservation initiatives developed by a mining company with the input of local communities led to many people having a positive view of the company, but there remained uncertainty about whether or not a social license was actually secured. Garnett et al. provide no indication about how a tacit, vague, and intangible social license could be interpreted or made to be tangible (Moffat et al. 2016).

\section{$\mathcal{C}$}

Garnett et al. argue that social license is "most useful when conceptualized as binary." But this very point is central to key criticisms of the term (Parsons \& Moffat 2014; Kendal \& Ford 2017; Overduin \& Moore 2017). Although it may be most useful from the viewpoints of proponents and is a feature of some readings of social licence originating in the mining industry (e.g., Shepard 2008; Moffat et al. 2016), this conceptualization does not fit with observed relations among companies, governments, and communities and continues to marginalise views that differ from licence seeker's perceived verdicts. Whose views are included in these assessments and whose are not? It is far from clear that government will operate in the interests of the community over powerful, vested, or self-interests. As Garnett et al. acknowledge, "existing conservation governance regimes are a product of the historical legacy of earlier political contest, which has had a patchy history around the globe." Any characterisation of social license as binary must treat seriously the question posed in the literature: How exactly does one know when one has one? Indeed, the inability to clearly articulate the presence of a social license risks making community- and stakeholderengagement processes even more opaque and subject to the whims of the politically 
powerful. This could even lead to increased conflict as the views of less powerful are supressed (Lester 2016).

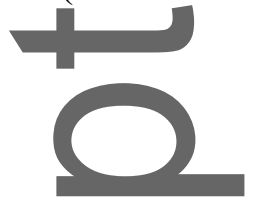

Garnett et al. also-introduce a new relationship between social and legal licenses -the (1) presence of a social license is an informal precursor to the legal granting of a regulatory license. That is, social license is an emergent property that exists where government believes "there is political gain, or at least no risk." Previous criticism of use of the term social license cautions that social and legal licenses must be understood in different terms (Moffat et al. 2016); social license is something that must be earned from communities and stakeholders. Identifying political gain as part of the granting process also suggests problematic power relationships under which government judgement, rather than a transparent process, shapes outcomes. Like the lack of certainty about the presence of a social license, one must ask: rese How are these judgements formed? This new conceptualisation is interesting, but it is not clear how it is useful in understanding relations between the community and conservation activities or how accurately it reflects use of the term social license within conservation.

These points highlight the need for robust social research to underpin further discussion on this topic. Garnett et al. (in press) argue that the definition of social license developed by Gunningham et al. (2004) "does not actually capture the way in which it is being used by mining companies or forestry operations." Yet Gunningham's (2004) definition was developed out of a carefully designed research project in which enterprise managers across 4 countries were interviewed. The outcomes of this research should not be abandoned lightly. Gunningham et al.'s (2004) definition may need to be refined in the context of conservation 
activities in 2018, but alternative definitions need to be tested before they can be adopted.

Garnett et al. believe their "definition of social license captures a more realistic application of the term," but research is needed to test this claim. There are a variety of well-established qualitative and quantitative traditions of social research that can be used to generate empirical evidence to support or refute these beliefs and a number of good examples of research on the use of the term social license in mining, forestry, and aquaculture (e.g. Gunningham et al. 2004; Leith et al. 2014; Moffat \& Zhang 2014; Overduin \& Moore 2017).

To develop this debate further, some key research questions must be tackled empirically. First, how are the various actors within conservation (government, community, and others) using the term social license? It is unclear whether use of the term in conservation is different from use of the term in other industries, such as mining and forestry, and whether the term is being used consistently by different actors. Many of the criticisms of social license depend on the way the term is used, and research is required to determine whether these criticisms are valid in a conservation context. Second, who benefits from framing support for conservation as a social license? The governance of conservation is increasingly complex and involves governments and ăgencies, nongovernmental organizations, corporations, and diverse community groups with different interests (Berkes 2007), and conservation activities inevitably lead to a range of trade-offs and sociopolitical conflict (Colvin et al. 2015). There is a risk that, as with criticisms of its use in mining and forestry, social license could be used to avoid meaningful engagement between conservation managers and different groups within the community (Parsons \& Moffat 2014).

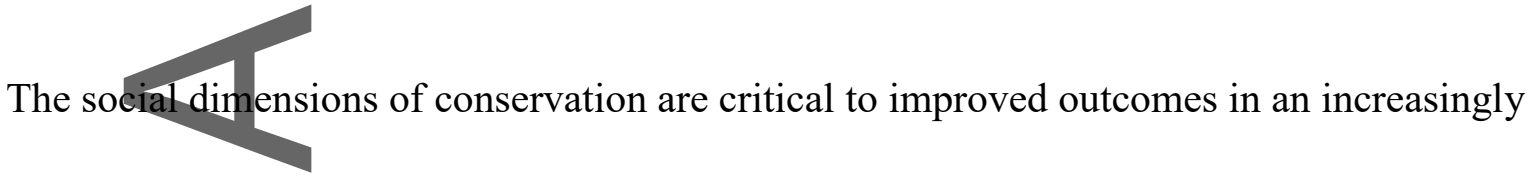
human-dominated and dynamic world (Sandbrook et al. 2013). It is not yet clear that the term 
social license is making a meaningful contribution to the description of these complex dimensions. However, despite our misgiving, social license may well have a useful role in the future of conservation. High-quality social research that contributes to a nuanced understanding of the role of social license could inform managers and policy makers about real levels of support for and acceptance of conservation activities by a diverse community.

\section{Literature Cited}

Berkes F. 2007. Community-based conservation in a globalized world. Proceedings of the National Academy of Sciences of the United States of America 104:15188-93.

Colvin RM,Witt GB, Lacey J. 2015. The social identity approach to understanding sociopolitical conflict in environmental and natural resources management. Global Environmental Change 34:237-246.

Garnett ST, Zander KK, Robinson CJ. 2018. Social license as an emergent property of politieal interactions: response to Kendal and Ford. Conservation Biology: in press.

Gunningham N, Kagan RA, Thornton D. 2004. Social license and environmental protection: why businesses go beyond compliance. Law \& Social Inquiry 29:307-341.

Kendal D, Ford RM. 2017. The role of social license in conservation. Conservation Biology DOI:-10.1111/cobi.12994.

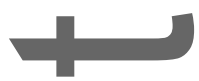

Leith P, Ogier E, Haward M. 2014. Science and social license: defining environmental sustainability of Atlantic salmon aquaculture in south-eastern Tasmania, Australia. Social Epistemology 28:277-296.

Lester L. 2016. Media and social licence: on being publicly useful in the Tasmanian forests 
conflict. Forestry 89:542-551.

Moffat K, LaceyJ, Zhang A, Leipold S. 2016. The social licence to operate: a critical review. Forestry 89:477-488.

Moffat IK, Zhang A. 2014. The paths to social licence to operate: an integrative model explaining community acceptance of mining. Resources Policy 39:61-70.

Overduin N, Moore ML. 2017. Social license to operate: not a proxy for accountability in water governance. Geoforum 85:72-81.

Parsons R, Moffat K. 2014. Constructing the meaning of social licence. Social Epistemology 28:340-363.

Sandbrook C, Adams WM, Büscher B, Vira B. 2013. Social Research and Biodiversity Conservation. Conservation Biology 27:1487-1490.

Shepard RB. 2008. Gaining a social license to mine. Mining.com, Vancouver, British Columbia. Available from http://www.mining.com/gaining-a-social-license-to-mine/ (accessed February 2018).

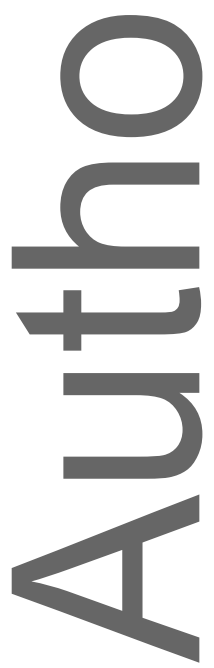

This article is protected by copyright. All rights reserved. 


\section{University Library}

\section{- M M N E R VA A gateway to Melbourne's research publications}

Minerva Access is the Institutional Repository of The University of Melbourne

Author/s:

Kendal, D;M. Ford, R

Title:

Need for empirical evidence to support use of social license in conservation: reply to Garnett et al.

Date:

2018-06-01

\section{Citation:}

Kendal, D. \& M. Ford, R. (2018). Need for empirical evidence to support use of social license in conservation: reply to Garnett et al.. CONSERVATION BIOLOGY, 32 (3), pp.737-739. https://doi.org/10.1111/cobi.13114.

Persistent Link:

http://hdl.handle.net/11343/283837 